\title{
Mating-induced cumulus-oocyte maturation in the shrew, Suncus murinus
}

\author{
T. Kaneko ${ }^{1}$, H. lida ${ }^{1}$, J. M. Bedford ${ }^{2}$, S. Oda ${ }^{3}$ and T. Mōri ${ }^{1 *}$ \\ ${ }^{1}$ Laboratory of Zoology, Graduate School of Agriculture, Kyushu University, Higashiku Hakozaki 6-10-1, \\ Fukuoka 812-8581, Japan; ${ }^{2}$ Department of Obstetrics and Gynecology, Weill Medical College of \\ Cornell University, NY 10021, USA; and ${ }^{3}$ Laboratory of Animal Management and Resources, \\ Graduate School of Bioagriculture Sciences, Nagoya University, Nagoya 464, Japan
}

The musk shrew, Suncus murinus, is an induced ovulator, the cumulus oophorus of which is unusual in several respects: it has no matrix, it always induces the acrosome reaction and it appears to be essential for fertilization. The present study documents distinctive features of the cumulus oophorus before and after ovulation, and of copulationinduced maturation of the ovulatory follicle, which has no antrum. In unmated females, potentially responsive ovarian follicles are distinguishable from large secondary follicles by differentiation of the granulosa into outer and inner cell layers, the latter being characterized particularly by intracellular glycogen deposits. The average number of responsive follicles equates with the number that ovulate. By about $10 \mathrm{~h}$ after mating, meiosis has reached metaphase II, with extrusion of the first polar body. Coincidentally, a cavity has developed between the inner and outer follicular layers, demarcating the smaller cells of the granulosa from the glycogen-rich cells of the cumulus oophorus. Subsequently, the glycogen becomes restricted primarily to the inner cumulus, and the corona cells began to retreat from the zona pellucida surface to form an unusual very distinct perizonal space that is clearly evident at the time of ovulation. The cumulus is stabilized by gap and tight junctions, and presents a smooth external surface that appears to initiate the acrosome reaction. After fertilization, at which time the zona pellucida becomes more resistant to both trypsin and dithiothreitol, the cumulus develops intercellular lacunae, and is eventually discarded about $15 \mathrm{~h}$ after ovulation.

\section{Introduction}

The cumulus oophorus of Suncus murinus is unusual compared with that of other eutherian mammals, in that its cells associate via structural junctions; it lacks a proteoglycan matrix and, as a result, it is unresponsive to hyaluronidase (Bedford et al., 1994). Another unusual feature is that the cumulus of $S$. murinus induces an acrosome reaction in all the spermatozoa that associate with it (Bedford et al., 1997a). Acrosome-reacted spermatozoa appear to penetrate the cumulus by selective invasion and killing of cumulus cells along a radial track (Kaneko et al., 2001). These characteristics are displayed by another crocidurine shrew, Crocidura russula (Bedford et al., 1997b). In the soricine shrew, Cryptotis parva, the cumulus is essential for fertilization in vitro, and any spermatozoa within it appear to lack the acrosome (Bedford et al., 1997C).

Although S. murinus is an induced ovulator (Dryden, 1969), it is not clear what characterizes the preovulatory follicle, how it changes during the mating-induced

${ }^{*}$ Correspondence

Email: tmohri@agr.kyushu-u.ac.jp maturation that results in ovulation, how it is ovulated and what is involved in its eventual loss. These questions are examined in the present study, which describes in detail the characteristics of developing follicles from the largest secondary stage until after ovulation.

\section{Materials and Methods}

Investigations were conducted in accordance with the National Research Council (NRC) publication Guide for Care and Use of Laboratory Animals (copyright 1996, National Academy of Science).

Shrews aged $\geqslant 3$ months, originating from stocks caught in Katmandu and Bangladesh, were raised at Kyushu University or at the Laboratory of Animal Management and Resources, Graduate School of Bioagriculture Sciences, Nagoya University. The shrews were housed individually on bedding of wood chips in plastic cages of $39 \mathrm{~cm} \times 21 \mathrm{~cm} \times 15 \mathrm{~cm}$ for males, and $35 \mathrm{~cm} \times 20 \mathrm{~cm} \times 12 \mathrm{~cm}$ for females, with a $12 \mathrm{~h}$ light: $12 \mathrm{~h}$ dark photoperiod, at $20-25^{\circ} \mathrm{C}$. Water and food were available ad libitum; the food was a commercial chow for trout, Hipro $5 p$ (Nippon Formula Feed Manuf. Co. Ltd, Yokohama). In the mating experiments, 


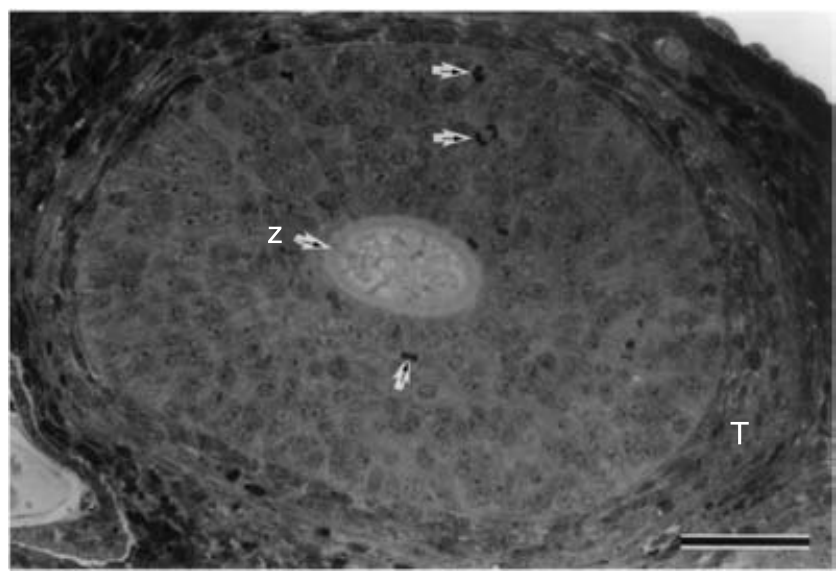

Fig. 1. Section of a large secondary follicle with about 14 follicular cell layers in an unmated Suncus murinus. Arrows show mitotic figures. T: theca; Z: zona pellucida. Toluidine blue staining. Scale bar represents $50 \mu \mathrm{m}$.

copulation occurred when a receptive female was introduced into the presence of a fertile male.

For studies of the follicles and the characteristics of the cumulus oophorus at different stages in mated animals, cumulus-oocyte complexes (COCs), ovaries and tubal ampullae containing COCs were fixed in 0.2 mol sodium cacodylate buffer $\mathrm{I}^{-1}, 1 \%(\mathrm{w} / \mathrm{v})$ paraformaldehyde-3\% $(\mathrm{w} / \mathrm{v})$ glutaraldehyde $\left(4^{\circ} \mathrm{C}\right.$, $\mathrm{pH} 7.4$; Karnovsky, 1965), dehydrated in a series of alcohol and embedded in epoxy resin. Thick sections $(1.5 \mu \mathrm{m})$ were stained with toluidine blue, and thin sections (approximately $60 \mathrm{~nm}$ ) were stained with uranyl and lead acetate. In addition, cumuli stripped from the tubal ampulla with fine forceps 15.5$16.0 \mathrm{~h}$ after mating were fixed in $1 \%$ paraformaldehyde$3 \%$ glutaraldehyde, embedded in $1.5 \%(\mathrm{w} / \mathrm{v})$ agar, postfixed in $1.3 \%(\mathrm{w} / \mathrm{v})$ osmium tetroxide, and embedded for electron microscopy. Unfertilized eggs were fixed in phosphate-buffered glutaraldehyde containing tannic acid (Mizuhira and Futaesaku, 1972), and post-fixed in $1.3 \%(\mathrm{w} / \mathrm{v})$ osmium tetroxide to examine the structure of the zona pellucida just after ovulation.

COCs were released from mature follicles with fine forceps at about $13.5 \mathrm{~h}$ after mating and from the tubal ampulla at about $16 \mathrm{~h}$ after mating to compare the affinity of the cumulus and zona pellucida for wheat germ agglutinin (WGA) before and after ovulation. After incubation with WGA peroxidase (WGA-HRP; $50 \mu \mathrm{g}$ $\mathrm{ml}^{-1}$ ) (EY Labs Inc., San Mateo, CA) in M199 at $4{ }^{\circ} \mathrm{C}$ for $20 \mathrm{~min}$, the COCs were washed in buffer, fixed in $3 \%(\mathrm{w} / \mathrm{v})$ glutaraldehyde in $0.1 \mathrm{~mol}$ sodium-cacodylate buffer $\mathrm{I}^{-1}(\mathrm{pH} 7.4)$, washed again, processed in $0.05 \%$ $(\mathrm{w} / \mathrm{v})$ 3,3'-diaminobenzidine tetrahydrochloride (DAB) for $20 \mathrm{~min}$ and then in $0.05 \%(\mathrm{w} / \mathrm{v}) \mathrm{DAB}-0.01 \% \mathrm{H}_{2} \mathrm{O}_{2}$ for $15 \mathrm{~min}$. Finally, the COCs were washed in buffer, embedded in $1.5 \%(\mathrm{w} / \mathrm{v})$ agar, dehydrated in a series of alcohol and embedded in epoxy resin; thick sections were cut with glass knives.
The character of the zona pellucida in $S$. murinus was measured against that of the mouse, Mus musculus, as reflected in its response to the thrust of a microneedle and to trypsin and dithiothreitol. Mouse (ICR) eggs were recovered from the ampulla $24 \mathrm{~h}$ after i.p. injection of $5 \mathrm{U}$ of equine chorionic gonadotrophin (eCG) (Teikokuzoki Pharmaceutical Co. Ltd, Tokyo). Unfertilized eggs were collected from the ampulla of $S$. murinus approximately $25.5 \mathrm{~h}$ after injection of $5 \mathrm{U}$ hCG (Mochida Pharmaceutical Co. Ltd, Tokyo), and fertilized eggs were recovered $25.5 \mathrm{~h}$ after injection of hCG and mating. Mouse oocytes were released from the cumulus by exposure to hyaluronidase, whereas those of $S$. murinus had to be isolated by rupturing the hyaluronidase-resistant cumulus with fine forceps. For physical studies, oocytes suspended in mKRB were picked up with a cell-holding micropipette (Sterile vacu tip, ICSI; Eppendorf, Hamburg) and a micro-needle with an orifice diameter of approximately $4 \mu \mathrm{m}$ (Sterile transfer tip-R; ICRI; Eppendorf) was inserted into the zona pellucida. In addition, the temporal response of the zona pellucida to trypsin and dithiothreitol in unfertilized and fertilized eggs of S. murinus was compared with that in unfertilized eggs of the mouse. The eggs, obtained as described above, were transferred to $\mathrm{mKRB}(\mathrm{pH} \mathrm{7.4)}$ containing either $0.5 \%(\mathrm{w} / \mathrm{v})$ pancreatic trypsin (Sigma Chemical Co., St. Louis, MO) or $0.1 \%$ dithiothreitol (Sigma Chemical Co.), after which the outline of the zona pellucida was studied over a period of $30 \mathrm{~min}$ by differential interference contrast (DIC) optics.

\section{Results}

\section{Unmated animals}

The ovary of $S$. murinus is enclosed in a bursa and has a slightly flattened ovoid shape of $1.5 \times 1.0 \mathrm{~mm}$. In sections of the unstimulated ovary it was easy to identify atretic follicles and primordial follicles, and to distinguish large secondary follicles from 'responsive' follicles, that is, those destined to ovulate approximately $13-14 \mathrm{~h}$ after a mating stimulus.

Large secondary follicles. The biggest secondary follicles had a diameter of 270-330 $\mu \mathrm{m}$ with about 14 layers of follicular cells and a well-developed theca (Fig. 1).

The oocytes had a large central germinal vesicle (GV) with mitochondria showing cristae that massed mostly in a perinuclear zone, and also adjacent to the oolemma (Figs 2-4). There were aggregates of smooth endoplasmic reticulum (sER) around the central mitochondria, with adjacent rough endoplasmic reticulum ( $\mathrm{rER}$ ), together also with small cortical granules (approximately $0.3 \mu \mathrm{m}$ ) beneath the oolemma. Some sections of rER expanded and transformed to $\mathrm{sER}$, whereas other sections formed annular layered plates with many vesicles, and ER 


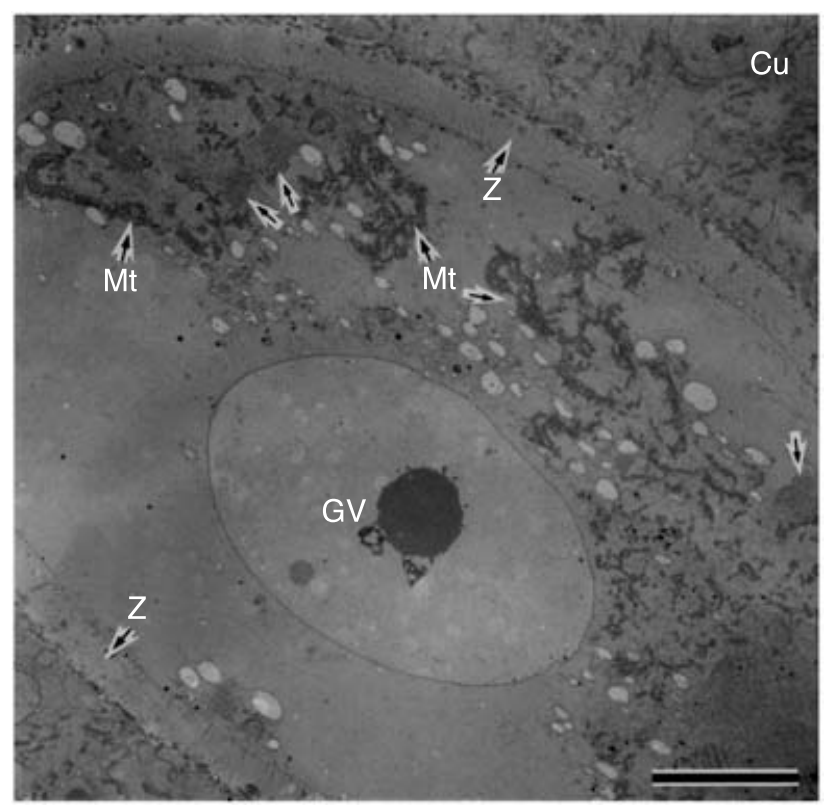

Fig. 2. Segment of a Suncus murinus oocyte within a large secondary follicle, showing a large central germinal vesicle (GV), aggregates of smooth endoplasmic reticulum with annular layered plates (arrows), and mitochondria (Mt). Note a region of high organelle density and a low density area. Cu: cumulus oophorus; Z: zona pellucida. Transmision electron micrograph. Scale bar represents $10 \mu \mathrm{m}$.

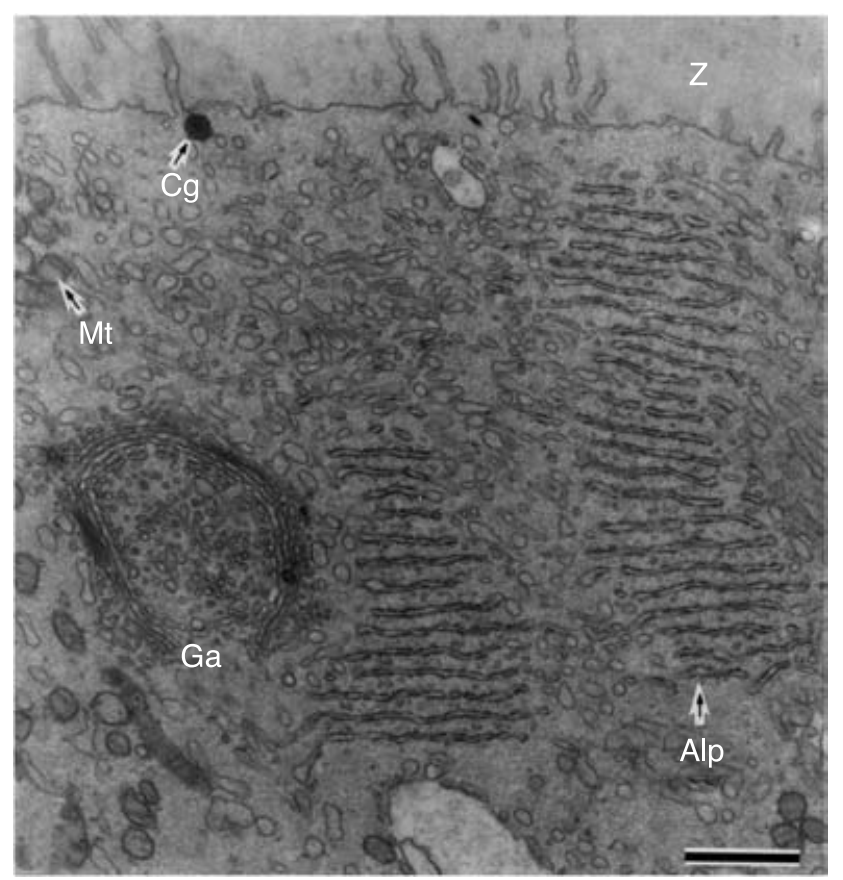

Fig. 3. Layered annuli associated with a clump of Golgi apparatus in a large secondary follicle from Suncus murinus. Alp: annular layered plates; Cg: cortical granule; Ga: Golgi apparatus; Mt: mitochondria; Z: zona pellucida. Transmission electron micrograph. Scale bar represents $1 \mu \mathrm{m}$.

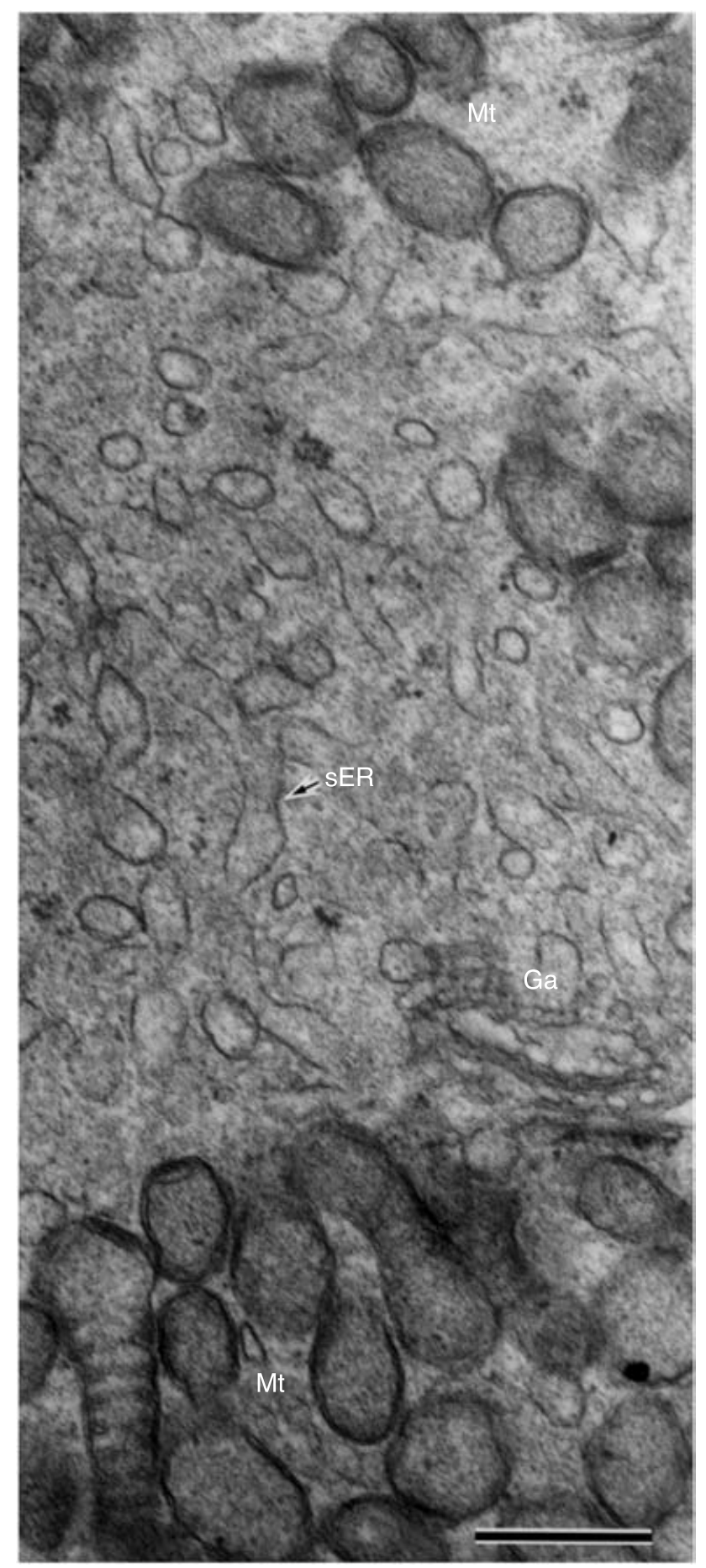

Fig. 4. Aggregates of smooth endoplasmic reticulum (sER) with many mitochondria (Mt) of an oocyte within a large secondary follicle from Suncus murinus. Ga: Golgi apparatus. Transmission electron micrograph. Scale bar represents $0.5 \mu \mathrm{m}$.

aggregates were also associated with clumps of Golgi vesicles. Multivesicular bodies and lipid were also limited to areas of sER and rER, whereas ribosomes and polysomes were scattered throughout the ooplasm. This distribution served to distinguish a region of high 


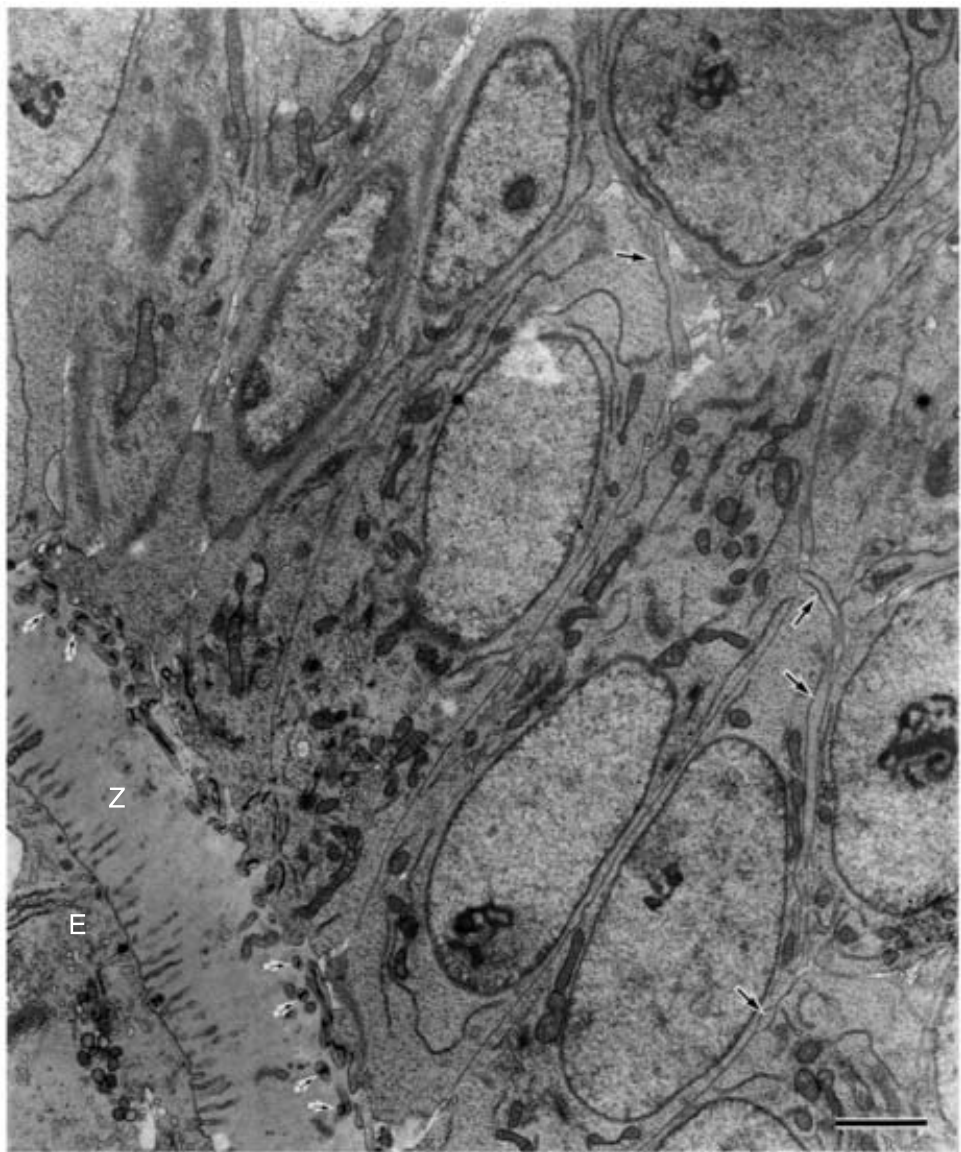

Fig. 5. Segment of a cumulus-oocyte complex (COC) in a large secondary follicle from Suncus murinus. The lateral surfaces of adjacent follicular cells are closely aligned and the whole forms a compact cellular mass. Straight microvilli extend uniformly from the oolemma to approach the centre of the zona pellucida (Z) and, in contrast to ovulated COCs, the oolemma and zona pellucida are closely apposed. The ends of the corona cell processes appear to entwine at the surface of the zona pellucida (small arrows). Large arrows denote thick cell processes in the interstices of the follicular cells. E: egg. Transmission electron micrograph. Scale bar represents $2 \mu \mathrm{m}$.

organelle density from a low density area consisting almost entirely of matrix. The zona pellucida remained in close apposition to the oolemma (Fig. 5) from which many slender microvilli extended almost to the centre of a zona pellucida of $2.5-2.9 \mu \mathrm{m}$ in thickness.

The follicular epithelium in large secondary follicles had about 14 cell layers, in which mitotic figures were common (Fig. 1). Processes extended from cells of the corona radiata to become somewhat intertwined at the surface of the zona pellucida, and then passed through the zona pellucida to reach the oolemma. Laterally, corona cells were tightly apposed almost without lacunae and with some tight junctions between them (Fig. 5).

Responsive follicles. There were 1-4 responsive follicles in each ovary in unmated females. These follicles were $300-400 \mu \mathrm{m}$ in diameter, had about 18 layers of cells and were distinguishable from the large non-responsive follicles by distinct internal and external cell layers (Fig. 6). Capillaries were present within a

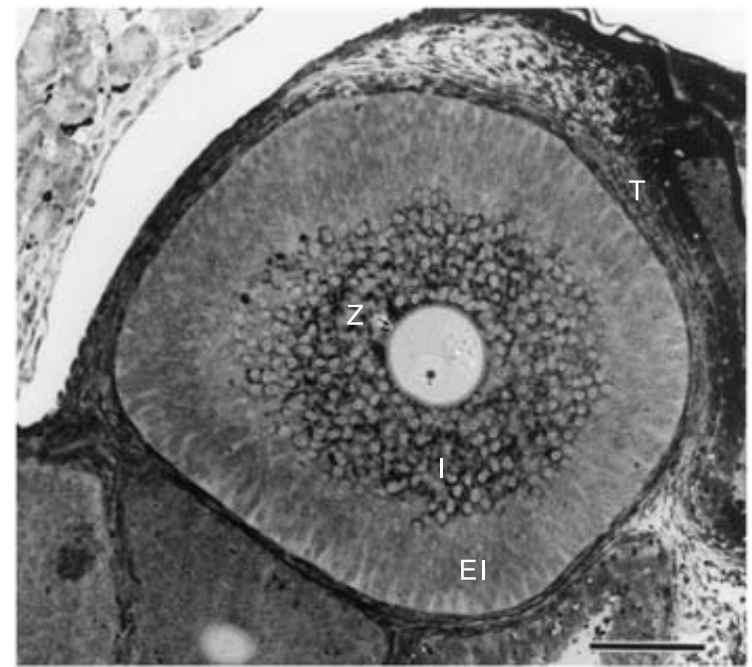

Fig. 6. Section of a responsive follicle from Suncus murinus. An external and an internal layer are recognizable. The cells of the internal layer were larger, had larger nuclei and contained much glycogen. El: external layer; I: internal layer; T: theca; Z: zona pellucida. Toluidine blue staining. Scale bar represents $50 \mu \mathrm{m}$. 


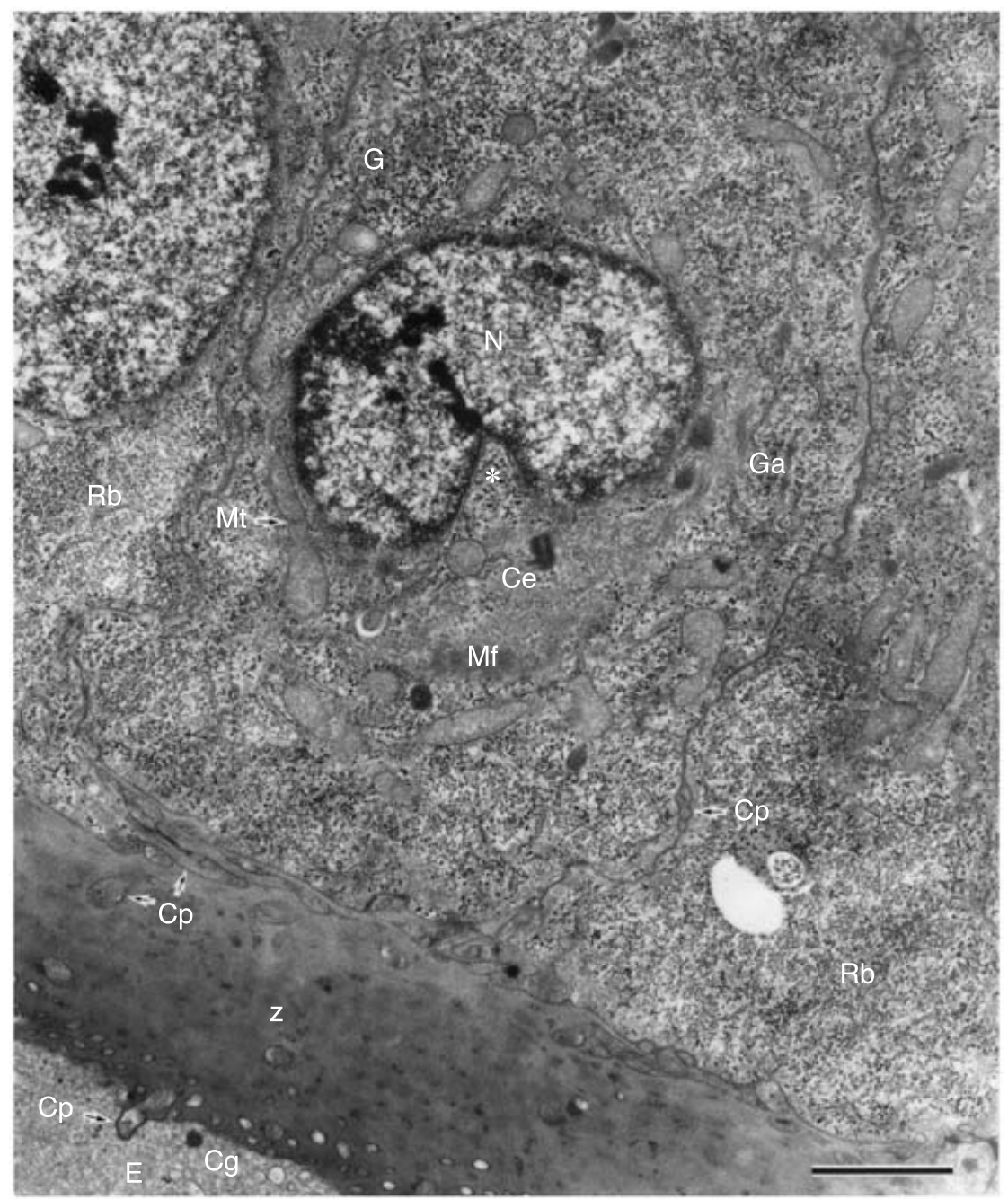

Fig. 7. Corona cell in a responsive follicle from Suncus murinus displaying many free ribosomes and extensive fields of black glycogen granules. Within an indentation of the nucleus, a pair of centrioles $(\mathrm{Ce})$ is surrounded by microfilaments $(\mathrm{Mf})$ with a small Golgi apparatus (Ga) nearby. Cp: cell processes; Cg: cortical granule; E: egg; G: glycogen granules; Mt: mitochondrion; N: nucleus; Rb: ribosomes; Z: zona pellucida; *: concavity of nucleus. Transmission electron micrograph. Scale bar represents $2 \mu \mathrm{m}$.

theca interna that was surrounded by 2-3 layers of long thin cells of the theca externa. The oocytes appeared very similar to those in large secondary follicles, except that the microvilli extended less far into the zona pellucida (Fig. 7).

Within the follicular epithelium, the 6-8 inner layers including the corona radiata were morphologically very different from the outer layers. Cells of the inner layer had a larger nucleus (approximately $8.6 \mu \mathrm{m}$ ) and were laden with glycogen (see also Suprasert et al., 1989), especially those of the 3-4 innermost layers (Figs 6 and 7). Processes from cells of the corona radiata traversed the zona pellucida to contact the oolemma. Long cell processes were present within the cell interstices of the inner layer (Fig. 8), but their terminations on the zona pellucida were less tortuous than in secondary follicles of equal size (compare with Figs 5 and 7). In the glycogen-laden inner layers the cell nuclei had a deep concavity near which a pair of centrioles was surrounded by microfilaments and a small Golgi apparatus. The local mitochondria tended to be branched rod-like forms with swollen finger-like cristae, and rER was dispersed rather widely in the cytoplasm, sometimes as arched lamellae (Fig. 8, inset), together with numerous ribosomes, polysomes, and some multivesicular bodies, microfilaments and small granules.

\section{Mated animals at 10.0-15.5 h after mating}

By 10-12 h after mating a cavity had formed between the inner glycogen-rich and outer layers of the preovulatory follicle. This cavity delineated the interface between 


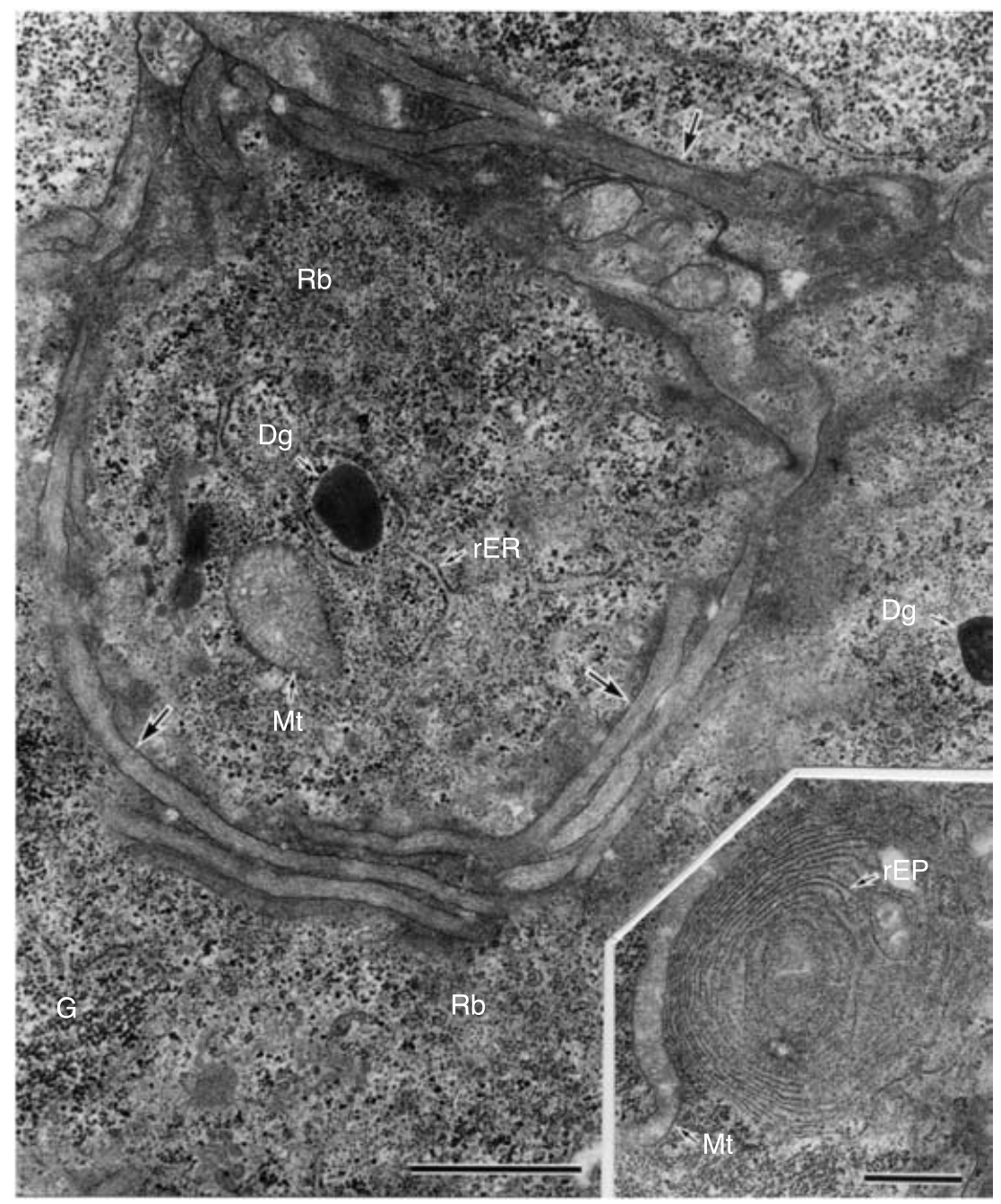

Fig. 8. Thick cell processes extending centripetally from follicular cells around corona radiata cells (compare with Fig. 5 arrows) from Suncus murinus. Transmission electron micrograph. Scale bar represents $1 \mu \mathrm{m}$. Inset: arched lamellae consisting of rough endoplasmic reticulum (rER). Arrows: cell processes; Dg: dense granule; G: glycogen; $\mathrm{Rb}$ : ribosomes; Mt: mitochondria. Transmission electron micrograph. Scale bar represents $1 \mu \mathrm{m}$.

future cumulus oophorus and the mural granulosa. At 10-12 h after mating the ovulatory oocyte had reached metaphase II, the first polar body had been extruded and a narrow perivitelline space had formed (Fig. 9). The distribution of oocyte mitochondria and sER was similar to that in non-stimulated responsive follicles, but the rER had disappeared and the Golgi stacks had decreased significantly.

At this stage, the outer layer of the cumulus was still irregular (Fig. 9) and it had little affinity for WGA (compared with the ovulated cumulus), whereas the outer half of the zona pellucida displayed a uniform binding of this lectin (see also Suprasert et al., 1989). Coincidentally, the corona cell processes began to pull away from the zona pellucida, beginning to form a perizonal space (Figs 9 and 10). There were no mitotic figures in the cumulus oophorus cells, the mitochondria appeared more swollen and the volume of $s E R$ and arched concentric lamellae of $\mathrm{rER}$ had increased, but with a coincident reduction in free ribosomes, Golgi stacks and associated vesicles. Moreover, the glycogen deposits were now essentially confined to the inner cells of the cumulus (Figs 9 and 10).

In contrast with the potential cumulus oophorus, the mural granulosa cells, which are eventually destined to become luteal cells, were smaller and had smaller nuclei than the potential cumulus oophorus cells (Fig. 9). The mural granulosa cells were characterized by long 


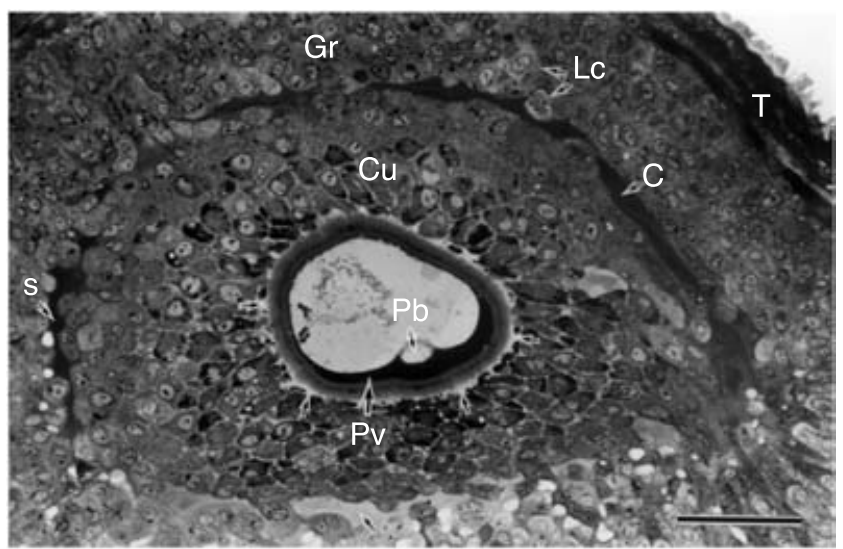

Fig. 9. A mature responsive follicle in Suncus murinus at 10-12 h after mating. A narrow cavity $(\mathrm{C})$ has formed between the cumulus oophorus $(\mathrm{Cu})$ containing glycogen and the glycogen-free mural granulosa $(\mathrm{Gr})$. Initial withdrawal of the corona radiata cells from the zona pellucida creates the beginning of a perizonal space (arrows). Lc: light cell; Pb: polar body; Pv: perivitelline space; T: theca. Toluidine blue staining. Scale bar represents $50 \mu \mathrm{m}$.

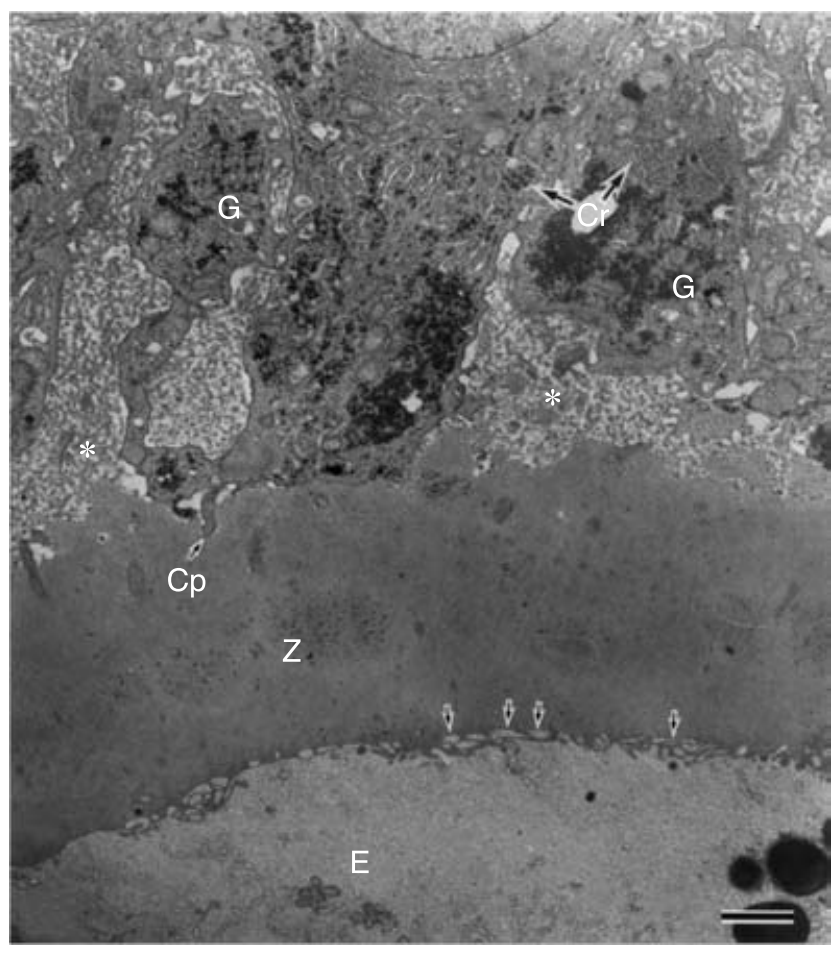

Fig. 10. Cumulus-oocyte complex of a responsive Suncus murinus follicle $15.5 \mathrm{~h}$ after mating. Withdrawal of corona cells (Cr) from the zona pellucida $(Z)$ creates a perizonal space $(*)$. Arrows: microvilli; Cp: cell processes; E: egg; G: glycogen. Transmission electron micrograph. Scale bar represents $2 \mu \mathrm{m}$.

mitochondria with prominent comb-like cristae, and by much rER with narrow cisternae, many dense Golgi stacks and lipid-like bodies.

\section{Ovulated COCs at $15.5 \mathrm{~h}$ after mating}

Within the ampulla of the Fallopian tubes, oocytes remained at metaphase II, with no change in the distribution of the mitochondria or sER. However, in histological sections the zona pellucida, now $6.5-9.0 \mu \mathrm{m}$ thick, was observed as two distinct layers: a denser inner region and a looser radially striated outer layer (Fig. 11). A bilayer organization of the zona pellucida was also indicated by the binding pattern of WGA (Fig. 11, inset), which had an affinity for the outer layer only. Soon after ovulation the perizonal space became wider (Fig. 12), and the cumulus cells were associated by way of multiple gap and adherens junctions, like pieces of a jigsaw puzzle (Figs 12 and 13). Coincidentally, the cumulus developed interstitial lacunae as some cells became progressively smaller and perhaps atrophic. After fertilization, which does not begin until at least 2-4 h after ovulation, the cumulus cells became more shrunken and were finally discarded about $30 \mathrm{~h}$ after mating or $15 \mathrm{~h}$ after ovulation.

The zona pellucida of $S$. murinus is somewhat less resistant to a microneedle than is that of the mouse. The outline of the zona pellucida of unfertilized $S$. murinus eggs was absent after $30 \mathrm{~min}$ exposure to trypsin, whereas that of the fertilized $S$. murinus eggs and the unfertilized mouse eggs still remained essentially intact (Fig. 14). However, after exposure to dithiothreitol (Fig. $14 d-f$ ), the zona pellucida of both the unfertilized and fertilized $S$. murinus egg swelled to a similar extent (Fig. 14e,d) and far more so than the zona pellucida of the unfertilized mouse egg (Fig. 14f).

\section{Discussion}

The Insectivora display a spectrum of types in regard to the character of the ovarian follicle and the COC produced from it at ovulation. Among the few species studied, one extreme is represented by some tenrecs, in which spermatozoa invade a follicle with no antrum and there fertilize eggs invested by a matrix-free cumulus (Strauss, 1950). At the other extreme, in moles, an antrum is formed and a semi-compact cumulus is ovulated that first adheres to the stigma on the ovarian surface; this shows some element of matrix formation as judged by its partial sensitivity to hyaluronidase (Bedford et al., 1999). In $S$. murinus, the final antrum is no more than a slit, with the spherical very compact matrix-free cumulus being released at ovulation as a free body (Dryden, 1969). Unlike that of most Eutheria, the cumulus in shrews appears to have an essential role in fertilization, and in crocidurines such as Suncus and Crocidura it is clearly the inducer of the acrosome reaction (Bedford et al., 1997ab; Kaneko et al., 2001).

In the musk shrew, the largest ovarian follicles fall into two categories. One is the secondary follicle that is unresponsive to the hormone changes associated with the 


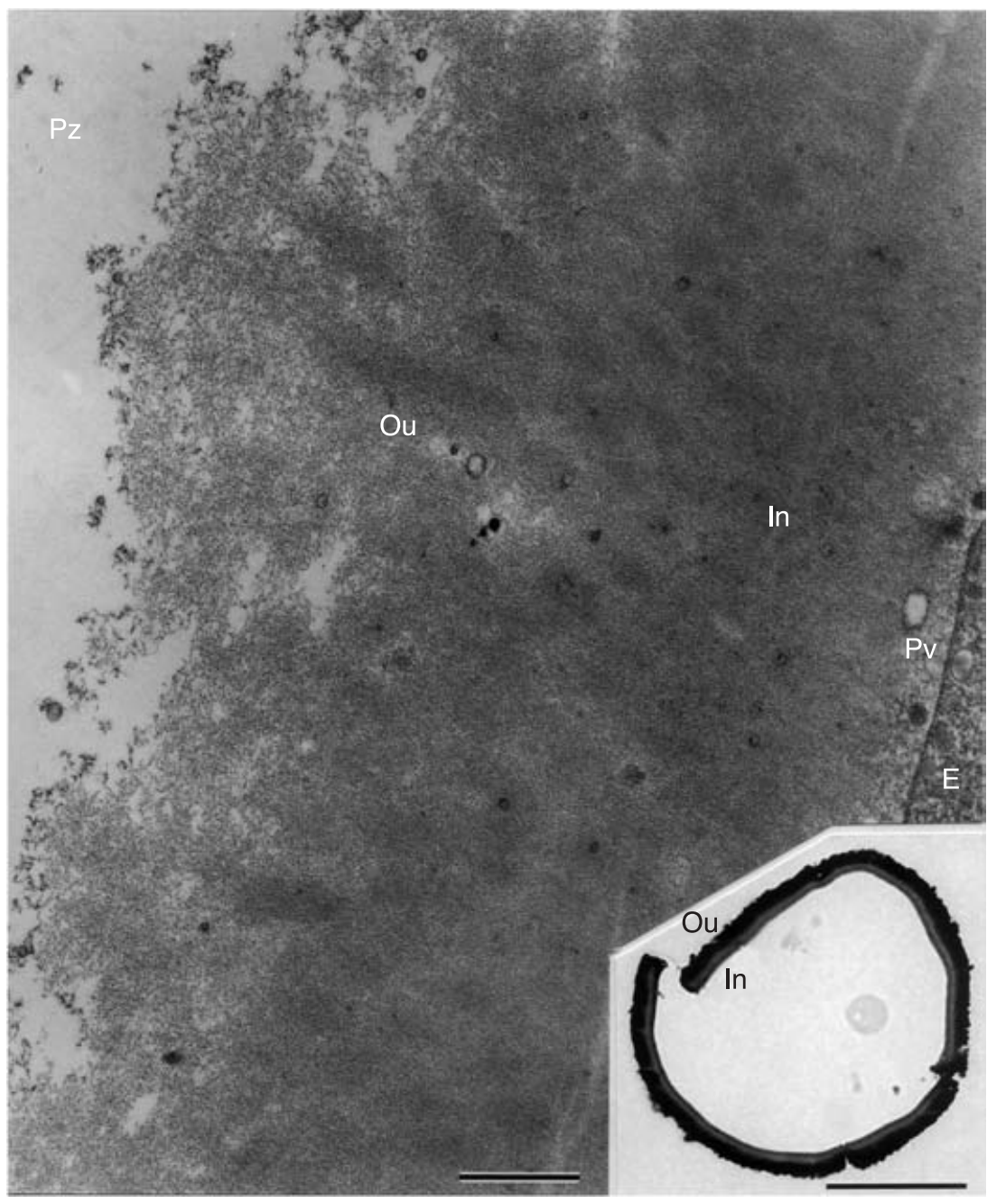

Fig. 11. Section of the zona pellucida of a cumulus-oocyte complex (COC) in the tubal ampulla of Suncus murinus immediately after ovulation. The zona pellucida displays a denser inner region (In) and a looser outer region $(\mathrm{Ou})$ with radial striations. Tannic acid fixation and single staining with lead acetate. E: egg; Pv: perivitelline space; Pz: perizonal space. Transmission electron micrograph. Scale bar represents $1 \mu \mathrm{m}$. Inset: section of a zona pellucida released from the COC. The inner region (In) of the zona pellucida had weak affinity for wheat germ agglutinin, as opposed to the well-defined affinity of the outer region $(\mathrm{Ou})$ of the zona pellucida. Scale bar represents $50 \mu \mathrm{m}$.

stimulus of mating, and in which cellular processes from the corona cells project through the zona pellucida to terminate on the oolemma, as in other mammals (Tanghe et al., 2002). The other ovarian follicles are the 'responsive' follicles that ovulate 14-15 h after mating (or after injection of eCG, hCG or LH; Dryden, 1969), and that equate to the number finally ovulated. Although the dynamics and controls of the transition to the 'responsive' state are quite unclear, and the initial appearance of the oocyte in the two follicle classes is similar, several features distinguish these types of follicle, even in unmated females. The 'responsive' follicles are slightly larger $(300-400 \mu \mathrm{m})$ and have about 18 cell layers as opposed to about 14 layers in secondary follicles (270$330 \mu \mathrm{m})$. Most striking, in the 'responsive' category the inner 6-8 layers comprised larger cells laden with glycogen, most obviously in those closest to the oocyte. Such cells were characterized also by several organelles: a cell centre, with a centriole, Golgi complexes and ribosomes adjacent to the concavity of the nucleus, and flanked by mitochondria and ER, all of which are indicative of significant metabolic activity, either actual or potential.

Although the significance of the cumulus cell glycogen is not yet clear, large accumulations have been observed in tertiary follicle cells of Crocidura russula 


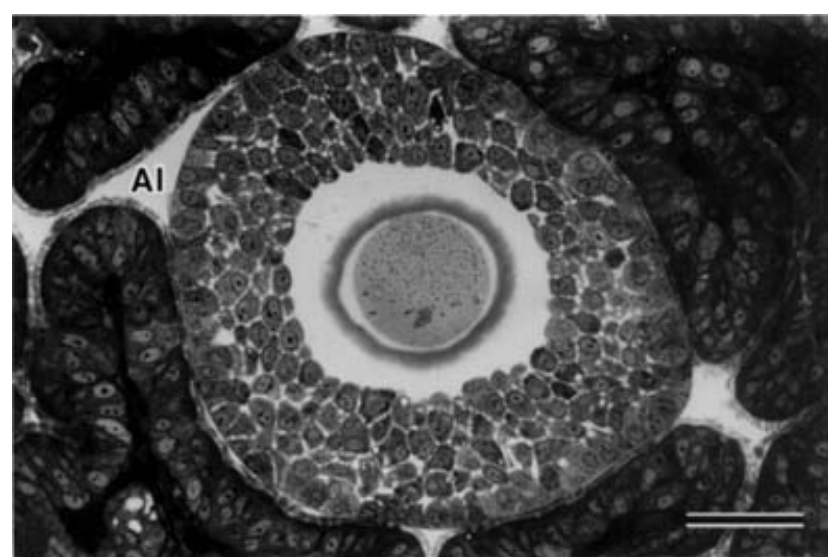

Fig. 12. Section of cumulus-oocyte complex in the tubal ampulla of $S$. murinus immediately after ovulation. The lumen is a labyrinth of narrow spaces between epithelial folds. The closely aligned cells of the outer layer of the cumulus oophorus are flat externally, in contrast to the more irregular inner surface. Al: ampullary lumen. Toluidine blue staining. Scale bar represents $50 \mu \mathrm{m}$.

captured in the winter (Kress, 1984) and of some other groups, particularly bats. The large amounts of glycogen in granulosa cells of mature follicles in hibernating vespertilionid bats (Nakano, 1928; Wimsatt and Kallen, 1957; Son et al., 1988) may represent a source of

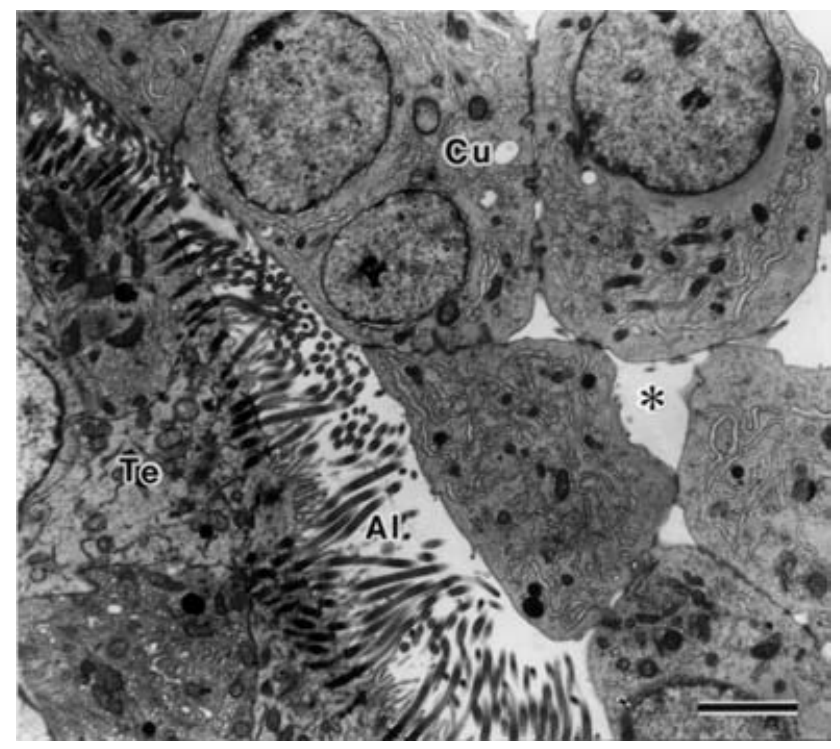

Fig. 13. Junctional zone between the cumulus surface and the ampullary epithelium in Suncus murinus. The surface of the outer cumulus cells $(\mathrm{Cu})$ is flat, and these adhere to each other by way of adherens and gap junctions. Al: ampullary lumen; Te: tubal epithelium; *: interstitial lacunae. Transmission electron micrograph. Scale bar represents $3 \mu \mathrm{m}$.
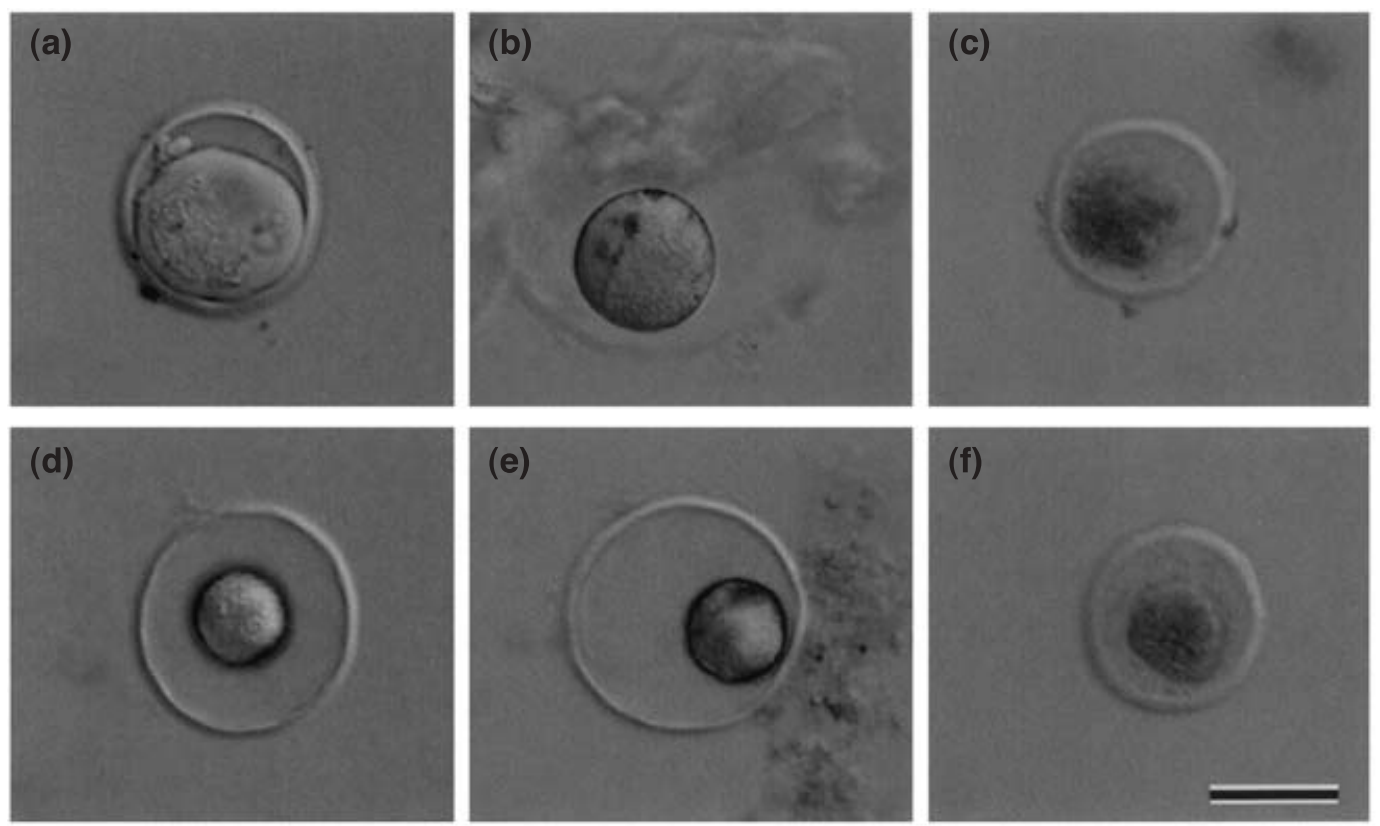

Fig. 14. Comparative responses of the zona pellucida to trypsin and dithiothreitol. (a,d) Fertilized Suncus murinus egg exposed to (a) trypsin or (d) dithiothreitol. (b,e) Unfertilized S. murinus egg exposed to (b) trypsin or (e) dithiothreitol. (c,f) Unfertilized Mus musculus egg exposed to (c) trypsin or (f) dithiothreitol. In the unfertilized $S$. murinus egg exposed to trypsin the zona pellucida has almost disappeared, whereas those of the fertilized $S$. murinus egg and the unfertilized mouse egg are less soluble. However, the zona pellucida of both the unfertilized and fertilized $S$. murinus egg appears to be more susceptible to dithiothreitol than that of the mouse egg. Differential interference contrast optics. Scale bar represents $100 \mu \mathrm{m}$. 
nutrition for the eggs (Wimsatt et al., 1966), but massive accumulations have also been seen in the follicles of a non-hibernating bat (Singh and Krishna, 1996).

Within the responsive follicle, a number of developments occurred in both the egg and the cumulus 10.0$15.5 \mathrm{~h}$ after mating (that is, before and immediately after ovulation). A cavity formed between the outer glycogenpoor granulosa layer destined to become corpus luteum, and the inner glycogen-rich cells that will constitute the discrete cumulus oophorus. The oocyte reaches metaphase II and extrudes the first polar body well before ovulation. However, there is a coincident withdrawal from the zona pellucida not only of the corona cell processes, but also of the corona cells themselves. This creates the unusual perizonal space clearly evident in the newly ovulated egg and within which additional reacted spermatozoa gather after fertilization (Bedford et al., 1997a). At this stage, cumulus cells are linked by gap and adherens junctions, and the outer cells present a smooth surface which appears to induce the acrosome reaction (Kaneko et al., 2001).

The many variations in form, character and longevity of the cumulus oophorous among eutherian mammals make it difficult to be sure of its evolutionary significance. Even among shrews the behaviour of the cumulus oophorous can differ quite markedly. In $S$. murinus cumulus oophorous remains as an inert structure for about $24 \mathrm{~h}$ around unfertilized eggs and for about $15 \mathrm{~h}$ around fertilized eggs, whereas that of the soricine shrew, Cryptotis parva, mucifies (that is, it secretes a hyaluronidase-sensitive matrix) and so becomes more diffuse in the oviduct a few hours after ovulation and fertilization (Bedford et al., 1997c). For S. murinus, not only does the cumulus induce the acrosome reaction, but its brittle quality allows it to be 'cracked' off the oocyte. As there is a snug relationship between ovulated COCs and the oviduct epithelium (Figs 12 and 13), it is possible that the compact nature of the cumulus might even afford some protection for the unfertilized egg. If so, the late accumulation of microfilaments in the cumulus cells might facilitate this. Finally, our microneedle manipulations of $S$. murinus zona pellucida and its reaction to trypsin and dithiothreitol indicate that the $S$. murinus zona pellucida is somewhat less rigid than that of the mouse, and that its physical character changes after fertilization as it does in other eutherian mammals.

\section{References}

Bedford JM, Cooper DM, Phillips DM and Dryden GL (1994) Distinctive features of the gametes and reproductive tracts of the Asian Musk Shrew, Suncus murinus. Biology of Reproduction 50 820-834
Bedford JM, Mori T and Oda S (1997a) The unusual state of the cumulus oophorus and of sperm behaviour within it, in the musk shrew, Suncus murinus. Journal of Reproduction and Fertility 110 127-134

Bedford JM, Phillips DM and Mover-Lev H (1997b) Novel sperm crypts and behavior of gametes in the Fallopian tube of the white-toothed shrew, Crocidura russula monacha. Journal of Experimental Zoology 277262 273

Bedford JM, Mock OB and Phillips DM (1997c) Unusual ampullary sperm crypts, and behavior and role of the cumulus oophorus, in the oviduct of the least shrew, Cryptotis parva. Biology of Reproduction 56 1255-1267

Bedford JM, Mock OB, Nagdas SK, Winfrey VP and Olson GE (1999) Reproductive features of the eastern mole (Scalopus aquaticus) and starnose mole (Condylura cristata) Journal of Reproduction and Fertility $\mathbf{1 1 7}$ 345-353

Dryden CL (1969) Reproduction in Suncus murinus. Journal of Reproduction and Fertility Supplement 6 377-396

Kaneko T, lida H, Bedford JM and Mori T (2001) Spermatozoa of the Shrew, Suncus murinus, undergo the acrosome reaction and then selectively kill cells in penetrating the cumulus oophorus Biology of Reproduction 65 544-553

Karnovsky MJ (1965) A formaldehyde-glutaraldehyde fixative of high osmolality for use in electron microscopy Journal Cell Biology 27137 (Abstract)

Kress A (1984) Ultrastructural studies on oogenesis in the shrew (Crocidura russula): I. The preantral follicle Journal of Morphology 179 59-71

Mizuhira V and Futaesaku $\mathbf{Y}$ (1972) New fixation of biological membranes using tannic acids Acta Histochemica et Cytochemica 5 233-237

Nakano O (1928) Ueber die Verteilung des Glycogens bei den zyklischen Veranderungen in den Geschlechtsorganen der Fledermaus. Und ueber die Nahrungsaufnahme der Spermien in dem weiblichen Geschlechtwege Folia Anatomy of Japan 6 S. 777

Singh UP and Krishna A (1996) Glycogen accumulation in the ovarian follicle of Indian vespertilionid bat, Scotophilus heathi during the period of delayed ovulation Zoological Science 13 893-897

Son SW, Mōri T, Yoon MH and Uchida TA (1988) Reproduction of two rare Pipistrellus species, with special attention to the fate of spermatozoa in their female genital tracts Journal of the Mammalogical Society of Japan 13 77-91

Strauss F (1950) Ripe follicles without antra and fertilization within the follicle; a normal situation in a mammal Anatomical Record $106251-$ 252

Suprasert A, Hirunagi K, Fujioka T and Yokoyama A (1989) Histochemistry of glycoconjugates in ovarian follicles of the adult house musk shrew, Suncus murinus. Acta Anatomica 136 269-278

Tanghe S, Soom AV, Nauwynck H, Coryn M and Kruif AD (2002) Minireview: functions of the cumulus oophorus during oocyte maturation, ovulation and fertilization Molecular Reproduction and Development $61414-424$

Wimsatt WA and Kallen FC (1957) The unique maturation response of the Graafian follicles of hibernating Vespertilionid bats and question of its significance Anatomical Record 129 115-131

Wimsatt WA and Parks HF (1966) Ultrastructure of the surviving follicle of hibernation and of the ovum-follicle cell relationship in the Vespertilionid bat Myotis lucifugus. Symposia of the Zoological Society of London 15 419-454

Received 6 January 2003

First decision 7 February 2003.

Revised manuscript received 4 July 2003.

Accepted 18 July 2003. 